\title{
Phosphodiesterase 4 Inhibition Impairs Cocaine-Induced Inhibitory Synaptic Plasticity and Conditioned Place Preference
}

\author{
Peng Zhong', Wei Wang', Fei Yu', Maressa Nazari', Xiaojie Liu' and Qing-Song Liu*,' \\ 'Department of Pharmacology and Toxicology, Medical College of Wisconsin, Milwaukee, WI, USA
}

\begin{abstract}
Endocannabinoid-mediated long-term depression of inhibitory synaptic transmission (I-LTD) in the ventral tegmental area (VTA) is implicated in cocaine-induced inhibitory synaptic plasticity and behavioral effects. It remains poorly understood, however, how this I-LTD is regulated and whether this regulation affects cocaine-seeking behavior. I-LTD requires cyclic adenosine $3^{\prime}, 5^{\prime}$-monophosphate (cAMP)dependent protein kinase A (PKA) signaling, raising the possibility that modulators of CAMP/PKA signaling may regulate I-LTD and the reinforcement behavior. Phosphodiesterase (PDE) 4 hydrolyses CAMP and terminates CAMP/PKA signaling. Here, we report that selective PDE4 inhibitors rolipram and Ro 20-1724 blocked I-LTD and acute depression of inhibitory postsynaptic currents (IPSCs) induced by $D_{2}$ dopamine receptor and cannabinoid $C B_{1}$ receptor agonists in VTA dopamine neurons. We also show that intra-VTA microinjections of PDE4 inhibitor rolipram impaired the acquisition, but not the expression, of conditioned place preference (CPP) to cocaine. Systemic administration of rolipram also increased CAMP response element-binding protein (CREB) phosphorylation and activation in the VTA. Together, our results suggest that blockade of cocaine-induced inhibitory synaptic plasticity (I-LTD) and enhancement of CREB activation are two putative cellular mechanisms by which PDE4 inhibition impairs the acquisition of cocaine CPP. Neuropsychopharmacology (2012) 37, 2377-2387; doi: 10.1038/npp.2012.93; published online 20 June 2012
\end{abstract}

Keywords: phosphodiesterase 4 (PDE4); endocannabinoid; long-term depression of inhibitory synaptic transmission (I-LTD); conditioned place preference (CPP); cAMP response element-binding protein (CREB)

\section{INTRODUCTION}

Cocaine is a monoaminergic transporter inhibitor that blocks the reuptake of dopamine, serotonin, and norepinephrine, leading to extracellular accumulation of these transmitters (Elliott and Beveridge, 2005). Enhanced dopamine transmission in the mesocorticolimbic dopamine pathway is a common property for many drugs of abuse, including cocaine. The mesocorticolimbic system consists of dopamine projections from the ventral tegmental area (VTA) of the midbrain to the nucleus accumbens (NAc), prefrontal cortex and other limbic forebrain regions (Swanson, 1982). Dopamine activates $\mathrm{D}_{1}$-like and $\mathrm{D}_{2}$-like receptors. $D_{1}$ receptors are $G_{s}$-coupled receptors that stimulate adenylate cyclase (AC), leading to increased cyclic adenosine $3^{\prime}, 5^{\prime}$-monophosphate (cAMP) accumulation and protein kinase $A$ (PKA) activity, whereas $D_{2}$ receptors are coupled to $G_{i / o}$ protein, causing the opposite effects (Anderson and Pierce, 2005; Neve et al, 2004). Repeated cocaine exposure induces cAMP-related neuroadaptations in the mesocorticolimbic system (Anderson and Pierce,

*Correspondence: Dr Q-S Liu, Department of Pharmacology and Toxicology, Medical College of Wisconsin, 870I Watertown Plank Road, Milwaukee, WI 53226, USA, Tel: + I 414955 8877, Fax: + I 4|4 456 6545, E-mail: qsliu@mcw.edu

Received 20 February 2012; revised 7 May 20 I2; accepted 9 May 2012
2005; Lu et al, 2003; Nestler, 2001). These adaptive changes have a critical role in the development of addictive behavior (Self et al, 1998).

The hydrolysis of cAMP and cyclic guanosine monophosphate (cGMP) by phosphodiesterases (PDEs) provides an important mechanism for regulating cAMP and cGMP levels (Conti et al, 2003). Multiple PDE subtypes are expressed in the brain, among them, type 4 PDE (PDE4) specifically terminates cAMP-dependent signaling (Lugnier, 2006; Zhang, 2009). PDE4 isoforms are widely distributed in the brain, including the hippocampus and the mesolimbic dopamine system (Cherry and Davis, 1999; Miro et al, 2002). Pharmacological blockade or genetic knockout of PDE4 enhances long-term potentiation (Barad et al, 1998; Chen et al, 2010; Navakkode et al, 2004; Rutten et al, 2008; Vecsey et al, 2009), improves performance in learning and memory (Barad et al, 1998; Li et al, 2011; Vecsey et al, 2009; Zhang et al, 2000, 2004), and produces antidepressant effects (Li et al, 2009; Zhang, 2009). Most relevant to this study are the findings that systemic administration of selective PDE4 inhibitors attenuates cocaine-induced locomotor sensitization (Janes et al, 2009), conditioned place preference (CPP) (Thompson et al, 2004), and selfadministration (Knapp et al, 1999). Although increased cAMP was postulated to be responsible, the cellular and synaptic mechanisms and specific brain regions involved in these behavioral effects remain obscure. 
We have shown that a pathophysiologically relevant concentration of cocaine enables repeated synaptic stimulation to induce long-term depression (LTD) of inhibitory postsynaptic currents (IPSCs) in VTA dopamine neurons of midbrain slices (Pan et al, 2008a). This LTD of IPSCs (ILTD) may underlie the reduction of $\mathrm{GABA}_{\mathrm{A}}$ receptormediated inhibition induced by repeated cocaine exposure (Liu et al, 2005) and the acquisition of cocaine CPP (Pan et al, 2011). The combined activation of $\mathrm{D}_{2}$ dopamine receptors and type I cannabinoid receptors $\left(\mathrm{CB}_{1}\right)$ and the resultant inhibition of cAMP/PKA signaling are required for the I-LTD induction (Chiu et al, 2010; Pan et al, 2008b). As PDE4 inhibitors enhance cAMP/PKA signaling by inhibiting cAMP breakdown (Lugnier, 2006), we hypothesized that PDE4 inhibitors disrupt I-LTD induction in VTA dopamine neurons, which may explain their effects on cocaine-seeking behavior. We tested this hypothesis by examining effects of PDE4 inhibitors on I-LTD and $\mathrm{D}_{2}$ and $\mathrm{CB}_{1}$ receptor agonistinduced depression of IPSCs in midbrain slices. We also examined whether intra-VTA microinjections of PDE4 inhibitors affected the acquisition and expression of cocaine CPP. Our results suggest that impairment of cocaineinduced inhibitory synaptic plasticity (ie, I-LTD) may constitute a mechanism for the effects of PDE4 inhibitors on cocaine-seeking behavior.

The increase in cAMP/PKA activity triggers the phosphorylation and activation of the cAMP-responsive element-binding protein (CREB) (Silva et al, 1998). Cocaine administration induces CREB phosphorylation (pCREB) in the NAc and VTA (Marin et al, 2009; Olson et al, 2005; Walters et al, 2003). CREB overexpression in the NAc attenuates cocaine-induced locomotor sensitization (Sakai et al, 2002) and CPP (Carlezon et al, 1998; Pliakas et al, 2001). CREB activation may provide a negative feedback mechanism to attenuate drug-seeking behavior. We therefore examined whether cocaine CPP and PDE4 inhibition altered pCREB expression in the VTA. Collectively, alterations of cocaine-induced inhibitory synaptic plasticity (ILTD) and PCREB expression may provide putative cellular mechanisms by which PDE4 inhibition attenuates cocaineseeking behavior.

\section{MATERIALS AND METHODS}

\section{Animals}

Male Sprague-Dawley rats (Charles River, Wilmington, $\mathrm{MA})$ were used for brain slice electrophysiology (P18-30), immunohistochemistry, and behavior experiments (300$350 \mathrm{~g}$ ). All experimental procedures were approved by the Institution's Animal Care and Use Committee of the Medical College of Wisconsin.

\section{Chemicals}

Cocaine hydrochloride, CNQX-Na, $\mathrm{AP}-5$, and all other common chemicals were purchased from Sigma-Aldrich (St Louis, MO). Forskolin, rolipram, Ro 20-1724, and WIN55,212-2 were from Tocris Bioscience (Ellisville, MO). For electrophysiology, forskolin, rolipram, Ro 20-1724, and WIN55,212-2 were dissolved in dimethylsulfoxide (DMSO) as a concentrated stock (final concentration of DMSO $\leqslant 0.05 \%$ ).
Control slices were treated in the same concentration of DMSO for similar exposure time. Cocaine was dissolved in saline $(0.9 \% \mathrm{NaCl})$. For i.p. and intra-VTA injections, rolipram was first dissolved in DMSO, and then diluted in saline solution to get final concentration of DMSO to $12.5 \%$. The same concentration diluted DMSO was used as vehicle controls. All drugs were prepared as concentrated stock solutions and stored at -20 or $-80^{\circ} \mathrm{C}$ before use.

\section{Slice Preparation}

Midbrain slices $(250 \mu \mathrm{m})$ from male Sprague-Dawley rats (P18-30) were prepared as described previously (Pan et al, 2008a). Slices were prepared at $4-6{ }^{\circ} \mathrm{C}$ in a solution containing (in mM): 110 choline chloride, $2.5 \mathrm{KCl}, 1.25 \mathrm{NaH}_{2} \mathrm{PO}_{4}, 0.5$ $\mathrm{CaCl}_{2}, 7 \mathrm{MgSO}_{4}, 26 \mathrm{NaHCO}_{3}, 25$ glucose, 11.6 sodium ascorbate, and 3.1 sodium pyruvate. Slices were incubated in oxygenated $\left(95 \% \mathrm{O}_{2} / 5 \% \mathrm{CO}_{2}\right)$ artificial cerebrospinal fluid (ACSF) containing (in $\mathrm{mM}$ ): $125 \mathrm{NaCl}, 3 \mathrm{KCl}, 2.5 \mathrm{CaCl}_{2}, 1$ $\mathrm{MgCl}_{2}, 1.25 \mathrm{NaH}_{2} \mathrm{PO}_{4}, 26 \mathrm{NaHCO}_{3}$, and 10 glucose and were allowed to recover for $\geqslant 1 \mathrm{~h}$.

\section{Electrophysiology}

Whole-cell recordings were made under infrared-differential interference contrast microscopy (Pan et al, 2008a). IPSCs were recorded from midbrain VTA dopamine neurons. Dopamine neurons were identified by the presence of large $I_{h}$ currents, rhythmic firing at low frequency and prominent after hyperpolarization (Johnson and North, 1992; Jones and Kauer, 1999; Liu et al, 2005). Glass pipettes (3-5 M 2 ) were filled with an internal solution containing (in $\mathrm{mM}$ ): $\mathrm{K}$-gluconate $100, \mathrm{KCl} 50$, HEPES 10, EGTA 0.2, $\mathrm{MgCl}_{2}$ 2, Mg-ATP 4, $\mathrm{Na}_{2} \mathrm{GTP} 0.3$, and $\mathrm{Na}_{2}$-phosphocreatine 10 at pH 7.2 (with $\mathrm{KOH})$. Series resistance (15-25 M $\Omega$ ) was monitored throughout the recordings and data were discarded if the resistance changed by $>20 \%$. All recordings were performed at $32 \pm 1{ }^{\circ} \mathrm{C}$ by using an automatic temperature controller (Warner Instrument, Hamden, CT).

\section{Animal Surgery, Intra-VTA Microinjection, and Histology}

Male Sprague-Dawley rats (300-350g) were anesthetized with ketamine $(90 \mathrm{mg} / \mathrm{kg}$, i.p.) and xylazine $(10 \mathrm{mg} / \mathrm{kg}$, i.p.) and placed in a stereotaxic device (David Kopf Instruments, Tujunga, CA). Guide cannulae (22 gauge, Plastics One) were bilaterally implanted $2.8 \mathrm{~mm}$ above the VTA at a $10^{\circ}$ angle using the following stereotaxic coordinates (from bregma, anteroposterior, $-5.6 \mathrm{~mm}$; mediolateral, $\pm 2.4 \mathrm{~mm}$; dorsoventral, $-7.8 \mathrm{~mm}$ ) (Paxinos and Watson, 1986). Rats were allowed to recover for $\sim 1$ week. Vehicle $(1 \mu \mathrm{l}$ per side) or rolipram $(0.5 \mu \mathrm{g}, 1 \mu \mathrm{l}$ per side) was bilaterally microinjected into the VTA via injector cannulae (33-gauge, Plastics One) that were placed inside the guide cannulae. The injector cannulae were connected through C313C connectors to $2 \mu \mathrm{l}-$ Hamilton micro-syringes. The injection rate was $1 \mu \mathrm{l}$ over $2 \mathrm{~min}$, and the injectors were kept in place for an additional $2 \mathrm{~min}$ to ensure adequate drug diffusion from the injector tip. The microinjection was made during cocaine or saline conditioning (Figure 5) or before CPP test (Figure 6). Histological verification of VTA cannula placements was 
performed using Cresyl Violet staining (Pan et al, 2011). Seven rats were excluded from behavioral analysis because cannula tips were outside of the VTA based on the stereotaxic atlas (Paxinos and Watson, 1986).

\section{Conditioned Place Preference}

CPP experiments were performed using a three-chamber CPP apparatus (Med Associates, St Albans, Vermont) (Pan et al, 2011). CPP protocol consisted of the following sessions: (1) pre-test (day 1): animals were allowed to explore both chambers for $20 \mathrm{~min}$ and time spent in each side was recorded. Rats showing unconditioned side preference $(\geqslant 180$ s disparity) were excluded $(n=6)$. (2) Conditioning (day 2-9): cocaine conditioning. Rats received cocaine injection $(15 \mathrm{mg} / \mathrm{kg}$, i.p. $)$ on days $2,4,6,8$ and were immediately confined to one chamber for $20 \mathrm{~min}$. On days 3 , 5,7 , and 9 , rats received saline injection $(0.9 \% \mathrm{NaCl}, 1 \mathrm{ml} / \mathrm{kg}$, i.p.) and were immediately confined to the opposite chamber for $20 \mathrm{~min}$. Saline conditioning. Rats received daily saline injection $(0.9 \% \mathrm{NaCl}, 1 \mathrm{ml} / \mathrm{kg}$, i.p.) and were immediately confined to one chamber for $20 \mathrm{~min}$ on days $3,5,7,9$ and were confined to the opposite chamber for $20 \mathrm{~min}$ on days 2 , 4, 6, and 8. (3) CPP test (day10): all of the animals were allowed to explore freely for $20 \mathrm{~min}$ between the two sides and time spent on each side was recorded. Subgroups of rats also received bilateral intra-VTA infusions of vehicle $(12.5 \%$ DMSO in saline) or rolipram $20 \mathrm{~min}$ before each cocaine or saline injection (Figure 4). Other groups of rats received bilateral intra-VTA infusions of vehicle or rolipram $20 \mathrm{~min}$ before CPP test but not during the conditioning phase (Figure 5).

\section{pCREB Immunohistochemistry}

Rats $(300-350 \mathrm{~g})$ received cocaine and saline conditioning and CPP test as described above except that no surgery was performed on these rats. In this way, VTA sections remained intact and undisrupted from intra-VTA microinjections, which facilitated accurate counting of pCREB-positive cells. Vehicle $(12.5 \%$ DMSO in $0.9 \% \mathrm{NaCl})$ or rolipram $(1 \mathrm{mg} / \mathrm{kg})$ was i.p. injected $20 \mathrm{~min}$ before each saline or cocaine conditioning. One hour after the CPP test, rats were anesthetized with sodium pentobarbital anesthesia $(60 \mathrm{mg} /$ $\mathrm{kg}$, i.p.) and then perfused through the aorta with $0.1 \mathrm{M}$ sodium phosphate-buffered saline (PBS) followed by $4 \%$ paraformaldehyde in $4 \%$ sucrose-PBS (pH 7.4). Brains were post-fixed, sectioned, and stained as we have described (Pan et al, 2011).

$D A B$ staining. Sections were incubated with pCREB antibody $(1: 250$, Cell Signaling Technology, Beverly, MA) at $4{ }^{\circ} \mathrm{C}$ for $48 \mathrm{~h}$. VTA sections were incubated with goat antirabbit IgG-HRP $(1: 100$, Bio-Rad, Hercules, CA) for $2 \mathrm{~h}$ at room temperature. Immunoreactivity was visualized with $0.05 \%$ DAB- $0.004 \% \quad \mathrm{H}_{2} \mathrm{O}_{2}$ in $0.1 \mathrm{M}$ ammonium phosphate buffer (APB) for $10 \mathrm{~min}$, and the reaction was stopped with APB for 5 min and then rinsed in PBS, dehydrated, and cover-slipped. Sections were imaged with a Nikon Eclipse 55i microscopy and analyzed by NIS Elements AR3.0 software (Nikon, Melville, NY). pCREBpositive neurons in the VTA were counted from the left or right side of the brain in two sections from each animal at approximately 5.2 and $5.4 \mathrm{~mm}$ posterior to bregma. The coordinates were determined by comparing the brain structures in the immunohistological sections with those in rat stereotaxic atlas (Paxinos and Watson, 1986). The number of pCREB-positive cells was normalized to the VTA area, which was determined with the aid of the same stereotaxic atlas.

Dual immunofluorescence staining. VTA sections were incubated with antibodies against PCREB $(1: 100)$ and tyrosine hydroxylase (TH, 1:300, Santa Cruz Biotechnology) at $4{ }^{\circ} \mathrm{C}$ for $48 \mathrm{~h}$. After washing with PBS, VTA sections were incubated in the secondary antibodies: anti-rabbit IgG Alexa Fluor 488 conjugate and anti-mouse IgG Alexa Fluor 555 conjugate (1:500, Cell Signaling) for $4 \mathrm{~h}$ at room temperature in the dark. The sections were analyzed by using a Nikon Eclipse TE-2000U confocal microscope.

\section{Statistics}

Data are presented as the mean \pm SEM. I-LTD (\%) was calculated as follows: $100 \times$ (mean amplitude of IPSCs during the final $10 \mathrm{~min}$ of recording/mean amplitude of baseline IPSCs). The acute depression of evoked IPSCs (\%) was calculated as follows: $100 \times$ (mean amplitude of IPSCs at last $5 \mathrm{~min}$ of drug application/mean amplitude of baseline IPSCs). IPSCs, evoked at 10 - to 20 -s intervals, were first averaged for every minute. The CPP score was calculated by the time spent in the cocaine-paired chamber minus the time spent in the saline-paired chamber. Data sets were compared with either Student's $t$-test (electrophysiology), one-way or two-way ANOVA followed by Tukey post hoc analysis (immunohistochemistry and behavior). Results were considered to be significant at $p<0.05$.

\section{RESULTS \\ PDE4 Inhibition Blocks I-LTD Induction in VTA Dopamine Neurons}

We have shown that decreased cAMP/PKA activity is required for I-LTD induction in the VTA (Pan et al, 2008b). PDE4 inhibition enhances cAMP activity by blocking its breakdown (Lugnier, 2006; Zhang, 2009). We examined whether selective PDE4 inhibitors rolipram and Ro 20-1724 affected I-LTD induction. Whole-cell voltage-clamp recordings (holding potential $-70 \mathrm{mV}$ ) were made from VTA dopamine neurons in midbrain slices prepared from 18- to 30-day-old rats. IPSCs were evoked by stimulating inhibitory synaptic afferents at $0.1 \mathrm{~Hz}$. Glutamate receptor antagonists CNQX $(20 \mu \mathrm{M})$ and AP-5 $(50 \mu \mathrm{M})$ were present in the ACSF throughout the experiments to block excitatory synaptic transmission. Consistent with our previous studies (Pan et al, 2008a, b), we found that repeated synaptic stimulation $(10 \mathrm{~Hz}, 5 \mathrm{~min})$ in the presence of a low concentration of cocaine $(3 \mu \mathrm{M})$ induced I-LTD $(63.4 \pm 8.2 \%$ of baseline, $n=6$; Figure 1a). This I-LTD was blocked by the continuous presence of selective PDE4 inhibitor rolipram $(1 \mu \mathrm{M})$ (92.7 $\pm 6.9 \%$ of baseline, $n=8, p<0.05 v s$ control) or Ro $20-1724(200 \mu \mathrm{M})(91.7 \pm 7.5 \%$ of baseline, $n=8, p<0.05 v s$ 

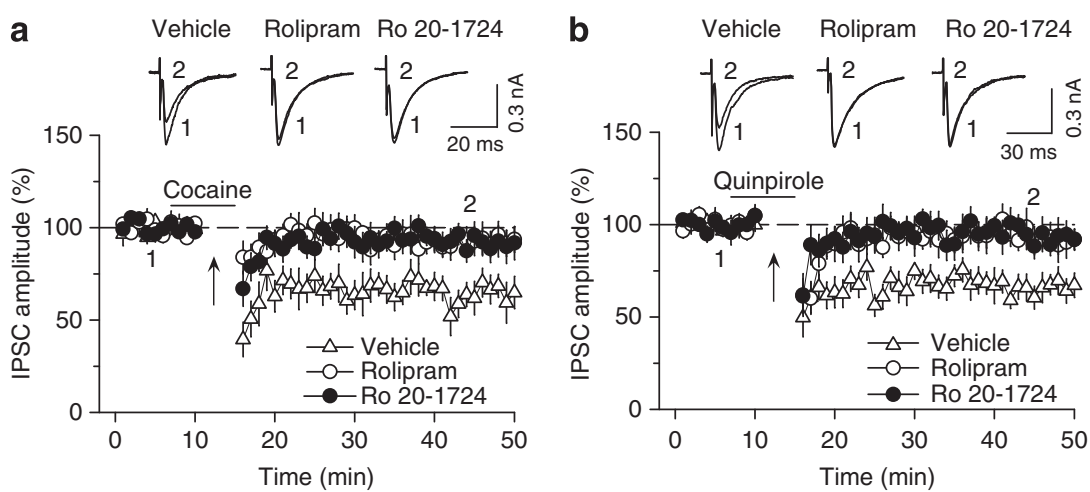

Figure I Selective PDE4 inhibitors rolipram and Ro 20- I724 blocked I-LTD in VTA dopamine neurons. (a) The presence of cocaine ( $3 \mu$ M; indicated by horizontal bar) during the $10 \mathrm{~Hz}$ stimulation (indicated by arrow ' $\uparrow$ ') induced I-LTD in VTA dopamine neurons $(n=6)$. This I-LTD was blocked by PDE4 inhibitors rolipram (I $\mu \mathrm{M} ; n=8 ; p<0.05$ vs control) and Ro 20- I 724 (200 $\mu \mathrm{M} ; n=8 ; p<0.05$ vs control). The PDE4 inhibitors were present throughout the whole-cell recordings. Sample IPSCs before (indicated by 'I') and after (indicated by ' 2 ') the $10 \mathrm{~Hz}$ stimulation are shown on the top. (b) The presence of $\mathrm{D}_{2}$ receptor agonist quinpirole $(\mathrm{I} \mu \mathrm{M})$ during the $10 \mathrm{~Hz}$ stimulation induced I-LTD in VTA dopamine neurons $(n=7)$. This I-LTD was blocked by rolipram ( $\mu$ M; $n=8 ; p<0.05$ vs control) or Ro $20-1724$ (200 $\mu$ M; $n=7 ; p<0.05$ vs control). Error bars indicate SEM.

control; Figure 1a). All statistics in this section were performed using Student's $t$-test. Similarly, I-LTD was induced by the combination of $10 \mathrm{~Hz}$ stimulation with $\mathrm{D}_{2}$ receptor agonist quinpirole $(1 \mu \mathrm{M})(69.2 \pm 6.6 \%$ of baseline, $n=7$; Figure $1 \mathrm{~b}$ ) but was blocked by either rolipram (93.5 $\pm 7.6 \%$ of baseline, $n=8, p<0.05 v s$ control) or Ro 20-1724 $(200 \mu \mathrm{M})(94.2 \pm 7.6 \%$ of baseline, $n=7, p<0.05 v s$ control; Figure 1b). These results indicate that PDE4 inhibition blocks I-LTD in VTA dopamine neurons.

\section{PDE4 Inhibition Potentiates IPSCs via Enhancement of cAMP/PKA Signaling}

To determine whether PDE4 inhibitors block I-LTD via inhibition of cAMP degradation, we examined the effects of bath application of rolipram and Ro 20-1724 on basal IPSCs. We found that bath application of either rolipram $(1 \mu \mathrm{M})$ or Ro 20-1724 $(200 \mu \mathrm{M})$ caused a small but significant increase in the amplitude of IPSCs (rolipram, $115.0 \pm 6.8 \%$ of baseline, $n=9$, Student's $t$-test, $p<0.05$; Figure 2a; Ro 20$1724,117.7 \pm 7.7 \%$ of baseline, $n=7, p<0.05$; Figure $2 \mathrm{~b}$ ). The enhancement of IPSC amplitude by either rolipram or Ro 20-1724 was abolished in the continuous presence of PKA inhibitor H-89 $(10 \mu \mathrm{M})$ (rolipram and H-89, $93.6 \pm 7.1 \%$ of baseline, $n=8, p<0.05$ vs rolipram alone; Figure 2a; Ro 20-1724 and H-89, $92.8 \pm 6.9 \%$ of baseline, $n=8, p<0.05$ vs Ro 20-1724 alone; Figure 2b).

Bath application of AC activator forskolin $(10 \mu \mathrm{M})$ with vehicle produced a modest increase in the amplitude of IPSCs (127.7 $\pm 8.3 \%$ of baseline, $n=6$, Student's $t$-test, $p<0.05$; Figure $2 \mathrm{c}$ ), whereas co-application of forskolin $(10 \mu \mathrm{M})$ with either rolipram or Ro 20-1724 produced significantly greater potentiation of IPSCs (forskolin and rolipram, $183.0 \pm 8.5 \%$ of baseline, $n=7, p<0.001$ vs forskolin or rolipram alone; Figure 2c; forskolin and Ro $20-1724,184.9 \pm 9.3 \%$ of baseline, $n=8, p<0.001 \quad v s$ forskolin or Ro 20-1724 alone; Figure 2d). Together, these results suggest that the PDE4 inhibitors enhance IPSCs by increasing cAMP/PKA activity.

\section{PDE4 Inhibition Impairs $\mathrm{D}_{2}$ and $\mathrm{CB}_{1}$ Agonist-Induced Depression of IPSCs}

We further investigated the mechanism for PDE4 inhibition-induced blockade of I-LTD. As activation of $\mathrm{D}_{2}$ and $\mathrm{CB}_{1}$ receptors is required for I-LTD induction (Pan et al, 2008b), we examined whether PDE4 inhibitors blocked downstream signaling activity induced by $\mathrm{D}_{2}$ and $\mathrm{CB}_{1}$ receptors. Bath application of $\mathrm{CB}_{1}$ receptor agonist WIN55,212-2 $(2 \mu \mathrm{M})$ produced a gradual depression of IPSCs $(66.7 \pm 6.8 \%$ of baseline, $n=7, p<0.01)$, and this depression was blocked by the continuous presence of PDE4 inhibitor rolipram $(1 \mu \mathrm{M})$ in the ACSF $(88.4 \pm 6.3 \%$ of baseline, $n=7, p<0.05$ vs control; Figure 3a). Similarly, bath application of $D_{2}$ receptor agonist quinpirole $(10 \mu \mathrm{M})$ induced depression of IPSCs ( $72.3 \pm 6.7 \%$ of baseline, $n=7$, $p<0.01$ ), which was also blocked by rolipram in the ACSF (95.2 $\pm 7.1 \%$ of baseline, $n=7, \quad p<0.05$ vs control; Figure 3b). In contrast, bath application of WIN55,212-2 $(2 \mu \mathrm{M})$ induced significant depression of IPSCs when rolipram $(1 \mu \mathrm{M})$ was loaded into the recorded postsynaptic neurons via the patch pipette, and the magnitude of the depression was not significantly different from that in the absence of postsynaptic rolipram (control, $66.7 \pm 6.8 \%$ of baseline, $n=7$; postsynaptic rolipram, $60.7 \pm 5.9 \%$ of baseline, $n=6, p>0.05$; Figure 3a). Postsynaptic loading of rolipram $(1 \mu \mathrm{M})$ also did not affect the acute depression of IPSCs induced by $\mathrm{D}_{2}$ agonist quinpirole $(10 \mu \mathrm{M})$ (control, $72.3 \pm 6.7 \%$ of baseline, $n=7$; postsynaptic rolipram, $66.7 \pm 7.7 \%$ of baseline, $n=7, p>0.05$; Figure $3 \mathrm{~b}$ ). Taken together, these results indicate that rolipram blocks $\mathrm{CB}_{1^{-}}$and $\mathrm{D}_{2}$-mediated acute depression of IPSCs by acting at presynaptic sites.

Finally, we examined the effects of another PDE4 inhibitor Ro 20-1724 on WIN55212-2- and quinpiroleinduced depression of IPSCs. In the continuous presence of Ro 20-1724 $(200 \mu \mathrm{M})$ in the ACSF, the acute depression of IPSCs induced by bath application of WIN55212-2 (2 $\mu$ l) or quinpirole $(10 \mu \mathrm{M})$ was blocked (WIN55212-2, $91.6 \pm 5.8 \%$ of baseline, $n=8, p<0.05 v s$ control; Figure 3c; quinpirole, $96.5 \pm 6.3 \%$ of baseline, $n=6, p<0.05 v s$ control; Figure $3 \mathrm{~d}$ ). 

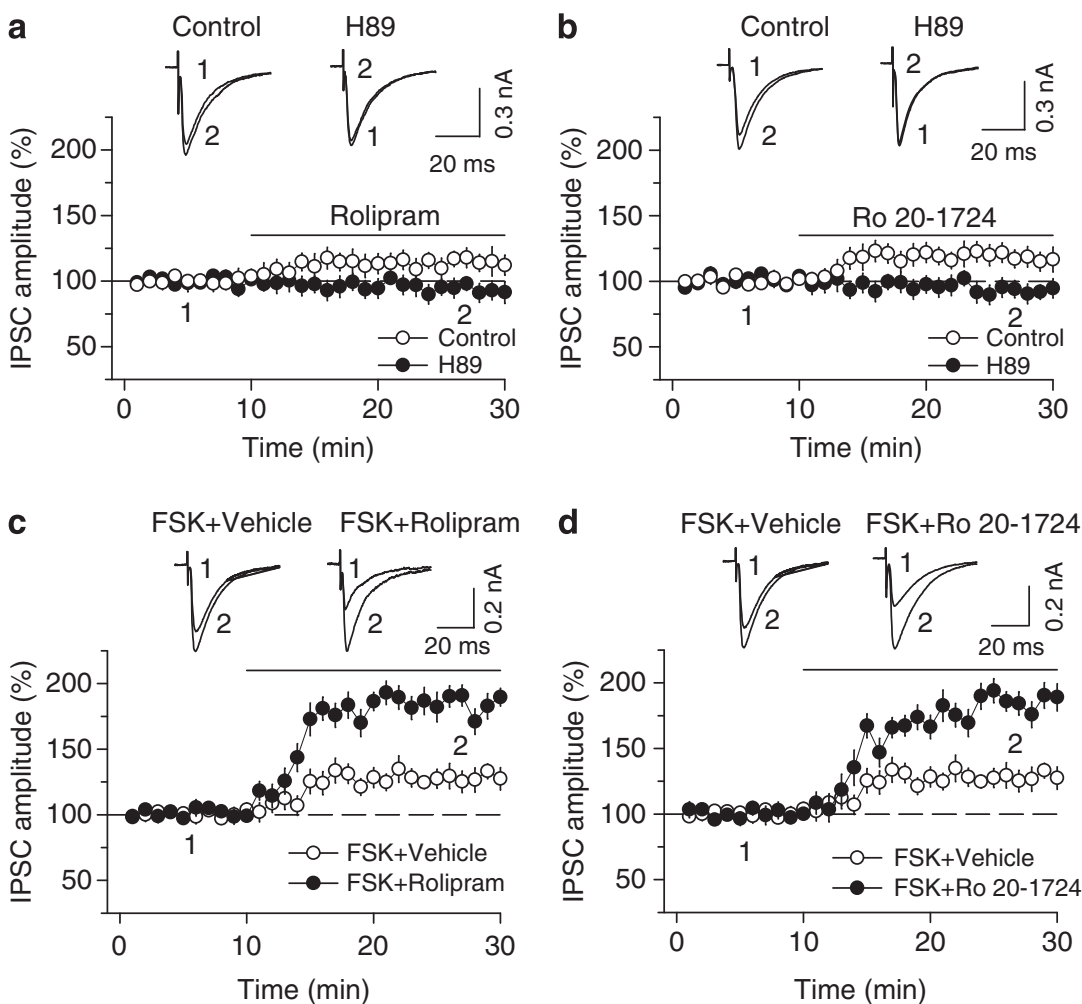

Figure 2 PDE4 inhibitors rolipram and Ro 20-I724 potentiate IPSCs by enhancing CAMP/PKA signaling. (a, b) Bath application of the PDE4 inhibitor rolipram (I $\mu$ M) (a) or Ro 20- I $724(200 \mu M)(b)$ increased the amplitude of evoked IPSCs $(n=9-8)$, and this potentiation was blocked by PKA inhibitor H89 ( $10 \mu \mathrm{M} ; n=7-8 ; p<0.05$ vs rolipram or Ro 20- 1724 alone). (c, d) Bath application of forskolin (FSK, I0 $\mu$ M) increased the amplitude of IPSCs ( $n=6$, $p<0.05)$. Co-application of forskolin with either rolipram (I $\mu$ M) (c) or Ro 20- 1724 (200 $\mu$ M) (d) significantly potentiated forskolin-induced increase in IPSCs $(n=7-8, p<0.0$ I vs forskolin, rolipram, or Ro 20-I724 alone). For comparison purpose, the same forskolin- alone data are shown in (c) and (d). Error bars indicate SEM.

We have shown previously that enhancement of cAMP with forskolin prevented WIN55,212-2 or quinpirole from depressing IPSCs in VTA dopamine neurons (Pan et al, 2008b). Similar mechanisms may explain why the PDE4 inhibitors block WIN55,212-2- or quinpirole-induced depression of IPSCs.

\section{Effects of Intra-VTA Microinjections of the PDE4 Inhibitors on the Acquisition of Cocaine CPP}

Having demonstrated that the PDE4 inhibitors block I-LTD, we next determined whether intra-VTA microinjections of PDE4 inhibitor rolipram affected the behavioral effects of cocaine. Rats were implanted with cannulae that allowed bilateral intra-VTA microinjections of drugs. After recovery, the rats underwent training and testing of CPP. The timeline for baseline preference test (pre-test), cocaine or saline conditioning, intra-VTA microinjections and CPP test is described in Figure 4a. During pre-test, rats did not exhibit significant differences in the time spent in each chamber $(p>0.05)$, indicating that there was no unconditioned place preference (Figure $4 \mathrm{~b}$ ). Then, cocaine or saline place conditioning was conducted once daily for 8 days (see Materials and Methods section). Vehicle (12.5\% DMSO in $0.9 \% \mathrm{NaCl}, 1 \mu \mathrm{l}$ per side) or rolipram $(0.5 \mu \mathrm{g}, 1 \mu \mathrm{l}$ per side) was bilaterally microinjected into the VTA via the preimplanted cannulae 20 min before each cocaine-pairing with a particular chamber (Figure 4a). Twenty-four hours after the last pairing, CPP was tested without any drug or vehicle administration (Figure 4a). A two-way ANOVA revealed that cocaine conditioning and intra-VTA rolipram microinjections had significant main effects on CPP scores (cocaine: $F_{(1,28)}=27.20, p<0.001$; intra-VTA microinjection: $F_{(1,28)}=5.20, p<0.05$; cocaine by intra-VTA microinjection interaction: $F_{(1,28)}=7.78, p<0.01$; Figure $\left.4 c\right)$. Tukey post hoc tests show that intra-VTA microinjections of rolipram produced a significant decrease in the CPP score in cocaine-conditioned rats $(p<0.01)$ but did not affect the CPP score in saline-conditioned rats $(p>0.05)$. Thus, intra-VTA microinjections of rolipram attenuate cocaine CPP without inducing CPP or conditioned place aversion in saline-conditioned rats.

We examined whether PDE4 inhibition in the VTA affects the expression of CPP to cocaine. Rolipram was bilaterally microinjected into the VTA 20 min before the CPP test, but not during the conditioning phase. The timeline for these experiments is described in Figure 5a. Pre-test indicates that rats did not show unconditioned place preference (Figure 5b). Rats received only cocaine conditioning, and no intra-VTA microinjections were made during place conditioning. Twenty minutes before the CPP test, vehicle ( $1 \mu \mathrm{l}$ per side) or rolipram $(0.5 \mu \mathrm{g}, 1 \mu \mathrm{l}$ per side) was bilaterally infused into the VTA. Rolipram did not significantly affect CPP to cocaine $(p>0.05$, Student's $t$ test), suggesting that the PDE4 inhibitor blocks the acquisition, but not the expression, of CPP to cocaine. 

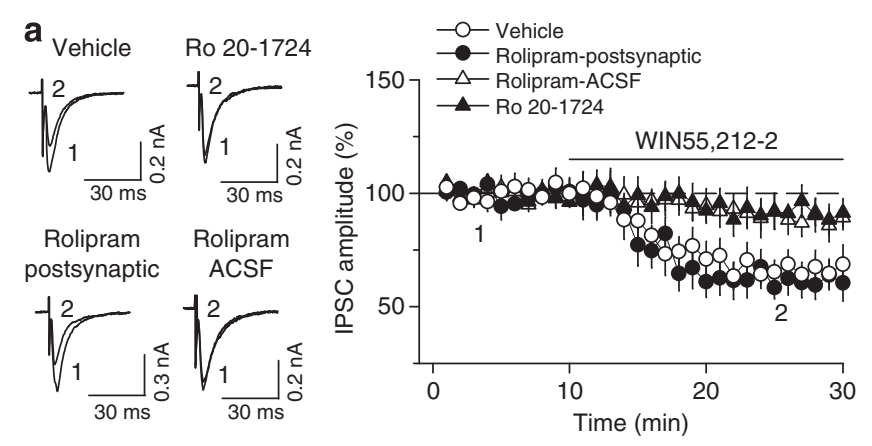

b

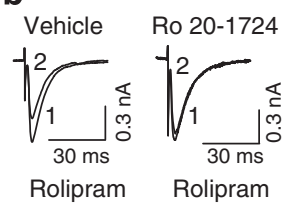
postsynaptic ACSF
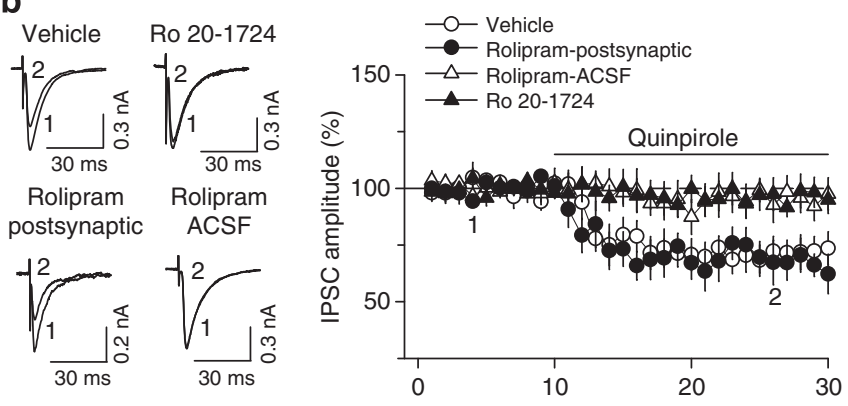

Figure 3 PDE4 inhibition impairs $C B_{1}$ and $D_{2}$ receptor agonist-induced depression of IPSCs. (a) Bath application of $\mathrm{CB}_{1}$ receptor agonist WIN55,2 I 2-2 (2 $\mu \mathrm{M})$ decreased the amplitude of IPSCs $(n=7)$, and this depression was abolished by the continuous presence of PDE4 inhibitor rolipram ( I $\mu \mathrm{M} ; n=7 ; p<0.05$ vs control) or Ro 20- I 724 (200 $\mu \mathrm{M} ; n=8$; $p<0.05$ vs control) in the ACSF. In contrast, postsynaptic loading of rolipram $(\mid \mu M)$ via recording patch pipette did not significantly affect WIN55,212-2-induced depression ( $n=6 ; p>0.05$ vs control). (b) Bath application of $D_{2}$ receptor agonist quinpirole $(10 \mu \mathrm{M})$ decreased the amplitude of IPSCS $(n=7)$, and this depression was abolished by the continuous presence of PDE4 inhibitor rolipram ( $\mu \mathrm{M} ; n=7 ; p<0.05$ vs control) or Ro 20-I724 (200 $\mu \mathrm{M} ; n=6 ; p<0.05$ vs control) in the ACSF. Postsynaptic loading of rolipram ( I $\mu \mathrm{M}$ ) via recording patch pipette did not significantly affect quinpirole-induced depression ( $n=7 ; p>0.05$ vs control). Error bars indicate SEM.

Figure $5 \mathrm{c}$ shows the locations of the cannula tips from the experiments in Figures 4 and $5 \mathrm{~b}$. These sites are representative of those used for intra-VTA microinjections. A total of 54 rats were used for intra-VTA microinjections and CPP tests, 7 rats with cannula tips outside of the VTA were excluded from analysis.

\section{Effects of I.P. Injections of the PDE4 Inhibitor Rolipram on the Acquisition of Cocaine CPP and PCREB}

Rolipram-induced cAMP increase can trigger the phosphorylation and activation of CREB (Li et al, 2011). CREB overexpression reduces cocaine reward (Carlezon et al, 1998; Pliakas et al, 2001). We therefore examined whether i.p. injections of PDE4 inhibitor rolipram affect cocaine CPP and pCREB expression in the VTA. Rats underwent cocaine or saline conditioning as described in Figure 4 except that they did not receive any surgery or intra-VTA microinjections. Rats did not show unconditioned place preference in pre-test ( $p>0.05$, data not shown). Rolipram $(1 \mathrm{mg} / \mathrm{kg}$ ) or vehicle was i.p. injected $20 \mathrm{~min}$ before each cocaine- or saline-pairing with a particular chamber on all conditioning days. Consistent with previous studies (Thompson et al, 2004), we found that cocaine $(15 \mathrm{mg} / \mathrm{kg})$ conditioning induced CPP to cocaine: $\left(F_{(1,20)}=11.13, p<0.01\right)$, whereas i.p. injection of rolipram significantly decreased CPP scores in cocaine-conditioned rats (rolipram: $F_{(1,20)}=23.77$, $p<0.001$; cocaine by rolipram interaction: $F_{(1,20)}=4.67$, $p<0.05$; Tukey post hoc test, cocaine and vehicle $v s$ cocaine and rolipram, $p<0.01$; Figure $6 \mathrm{a}$ ).

One hour following the CPP test, rats were killed and immunohistochemistry was performed to detect PCREB in the VTA, using antibodies against PCREB. We found that cocaine or rolipram produced significant increases in the number of pCREB-positive cells in the VTA (cocaine: $F_{(1,20)}=20.96, p<0.001$; rolipram: $F_{(1,20)}=29.21, p<0.001$; cocaine by rolipram interaction, $F_{(1,20)}=5.65, p<0.05$; Figure 6b). Tukey's post hoc test shows that rolipram significantly increased pCREB-positive cells in saline$(p<0.001)$ or cocaine-conditioned rats $(p<0.05)$. To determine whether pCREB is expressed in dopamine neurons, we performed dual immunostaining for pCREB and TH in VTA sections from rolipram plus cocaine-treated rats. Most of dopamine neurons ( $86 \pm 5 \%, n=3$ rats) were co-stained with pCREB. pCREB was expressed in both $\mathrm{TH}^{+}$ dopamine neurons and $\mathrm{TH}^{-}$non-dopamine neurons (mainly GABAergic neurons) (Figure 7).

\section{DISCUSSION}

In this study, we demonstrate that PDE4 inhibitors rolipram and Ro 20-1724 blocked I-LTD and enhanced CREB activation in the VTA. We also show that intra-VTA microinjections of PDE4 inhibitors impaired the acquisition, but not the expression, of cocaine CPP. Given that both inhibitory synaptic plasticity (I-LTD) (Pan et al, 2011) and CREB (Carlezon et al, 1998; Pliakas et al, 2001) are implicated in cocaine reward, our results have identified novel mechanisms for PDE4 inhibition-induced impairment of the acquisition of CPP to cocaine.

We have shown that repeated cocaine treatments $(15 \mathrm{mg} /$ kg, i.p.) in vivo for 5-7 days reduce the strength of GABAergic inhibition onto VTA dopamine neurons (Liu et al, 2005). Further experiments suggest that I-LTD may constitute a cellular mechanism for cocaine-induced reduction of GABAergic inhibition. First, I-LTD could be induced under conditions that mimic in vivo cocaine exposure (Pan et al, 2008a). The presence of $3 \mu \mathrm{M}$ cocaine enables repeated synaptic stimulation to induce I-LTD. Microdialysis studies indicate that the peak cocaine concentration in the mesolimbic dopamine system is approximately $2-5 \mu \mathrm{M}$ following i.p. injection of cocaine $(15 \mathrm{mg} / \mathrm{kg})$ in the rat (Maisonneuve and Kreek, 1994). Second, we showed that in vivo administration of antagonists to $\mathrm{D}_{2}$ receptors and $\mathrm{CB}_{1}$ receptors, which are required for I-LTD, also prevented cocaine-induced reduction of GABAergic inhibition (Pan et al, 2008a). Third, we found that repeated cocaine exposure in vivo occluded the subsequent induction of I-LTD ex vivo (Pan et al, 2008a). The above experiments suggest that I-LTD and cocaine-induced reduction of GABAergic inhibition share common mechanisms and may be causally related. However, it remains poorly understood how this I-LTD is regulated and whether this regulation is behaviorally relevant. 
a
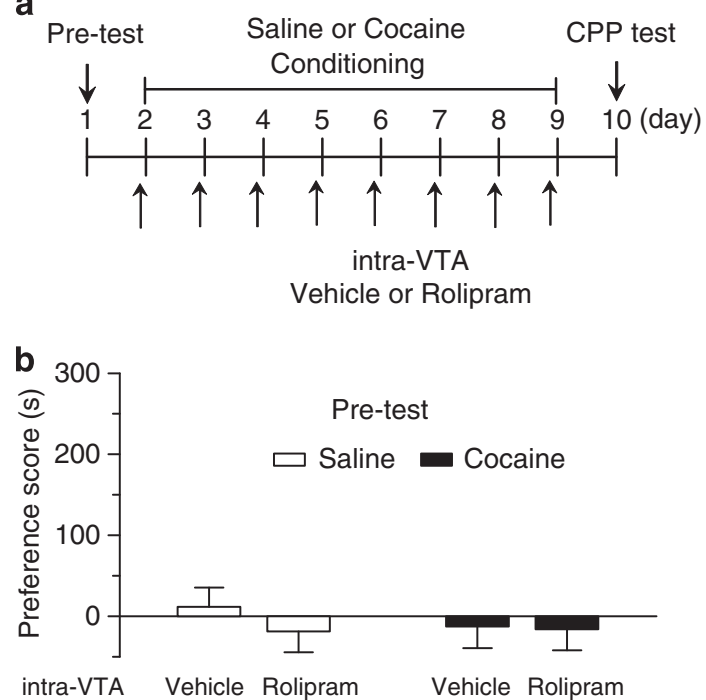

C

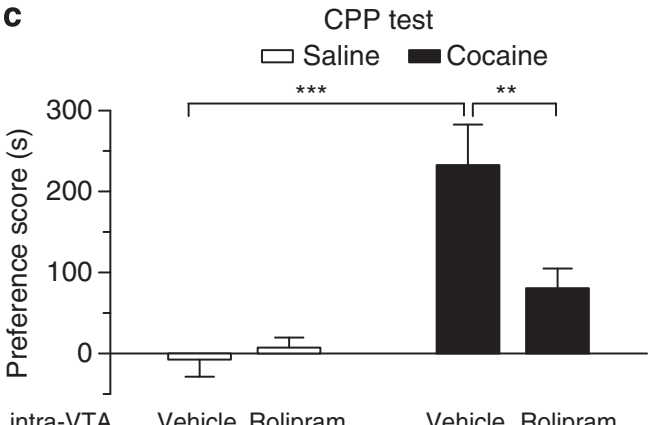

intra-VTA Vehicle Rolipram Vehicle Rolipram

Figure 4 Intra-VTA microinjections of the PDE4 inhibitor rolipram during the conditioning phase attenuated the acquisition of CPP to cocaine. (a) Timeline of drug treatment and behavioral paradigm. Groups of rats received saline and cocaine place conditioning once daily for 8 days. Vehicle $(|\mu|)$ or rolipram $(0.5 \mu \mathrm{g},|\mu|)$ was bilaterally infused into the VTA 20 min before each saline- or cocaine-pairing. (b) Pre-test indicates that rats did not exhibit significant baseline bias in place preference in all groups $(n=7-9 ; \quad p>0.05)$. (c) Intra-VTA infusions of rolipram significantly attenuated CPP in cocaine-conditioned rats but did not affect CPP scores in saline-conditioned rats $\left(n=7-9\right.$; ${ }^{* *} p<0.0 \mathrm{l}$, **** $\left.p<0.00 \mathrm{I}\right)$. Error bars indicate SEM.

We have shown that the decrease in presynaptic cAMP/ PKA activity is required for I-LTD induction in the VTA (Pan et al, 2008b), raising the possibility that modulation of the cAMP/PKA signaling pathway may affect I-LTD and cocaine-seeking behavior. cAMP is mainly hydrolyzed and degraded by PDE4 (Conti et al, 2003). We show here that PDE4 inhibitors rolipram and Ro 20-1724 blocked I-LTD in VTA dopamine neurons. The observed effects on I-LTD are most likely mediated by the inhibition of cAMP breakdown. Rolipram and Ro 20-1724 enhanced the amplitude of IPSCs, and this enhancement was blocked by PKA inhibitor $\mathrm{H}-89$. These PDE4 inhibitors greatly potentiated forskolin-induced enhancement of IPSCs. Forskolin is known to activate AC to increase intracellular cAMP levels (Awad et al, 1983). The potentiation of forskolin-induced response by the PDE4 inhibitors can be attributable to their inhibition of cAMP breakdown.

Our previous studies indicate that activation of presynaptic $\mathrm{D}_{2}$ and $\mathrm{CB}_{1}$ receptors leads to decreases in presynaptic cAMP/PKA activity, resulting in 1-LTD induction (Pan et al, 2008a,b). We show here that bath application of rolipram and Ro 20-1724 blocked the acute depression of IPSCs induced by $\mathrm{CB}_{1}$ agonist WIN55212-2 and $\mathrm{D}_{2}$ agonist quinpirole, whereas postsynaptic loading of rolipram did not significantly affect WIN55212-2- and quinpirole-induced depression of IPSCs. These results suggest the PDE4 inhibitors act on presynaptic sites to block the $\mathrm{CB}_{1}$ and $\mathrm{D}_{2}$ receptor-mediated depression of IPSCs. During I-LTD induction, activation of presynaptic $\mathrm{D}_{2}$ and $\mathrm{CB}_{1}$ receptors results in decreases in presynaptic CAMP/ PKA activity (Pan et al, 2008b), whereas PDE4 inhibitors rolipram and Ro 20-1724 increased cAMP/PKA activity and curtailed the downstream effects of $\mathrm{D}_{2}$ and $\mathrm{CB}_{1}$ receptor activation. This may explain why these inhibitors blocked ILTD induction.

We demonstrated that intra-VTA microinjection of the PDE4 inhibitor rolipram blocked the acquisition of cocaine CPP. Possible mechanisms for the observed behavioral effects include the following. First, given that I-LTD is critically implicated in the acquisition of cocaine CPP (Pan et al, 2011), we suspect that the blockade of I-LTD may constitute a mechanism by which the PDE4 inhibition impaired cocaine $\mathrm{CPP}$. Second, $\mathrm{D}_{2}$ and $\mathrm{CB}_{1}$ receptors have an important role in cocaine and morphine reward (Chaperon et al, 1998; Maldonado et al, 1997). We found that the acute depression of IPSCs induced by either the $\mathrm{D}_{2}$ receptor quinpirole or $\mathrm{CB}_{1}$ receptor agonist WIN55212-2 was blocked by rolipram and Ro 20-1724. Consistent with our findings, previous studies have shown that rolipram produces greater inhibition of hyperlocomotion induced by methamphetamine and morphine than by a $D_{1}$ receptor agonist, suggesting that PDE4 may regulate cAMP signaling at $\mathrm{D}_{2}$ receptors (Mori et al, 2000). Third, we found that rolipram administration increased the number of PCREB-positive neurons in the VTA. Repeated cocaine administration increased pCREB and activation in the mesolimbic dopamine pathways (Olson et al, 2005; Walters et al, 2003). Downregulation of CREB function by viral overexpression of a dominant-negative CREB mutant in the NAc enhances cocaine CPP (Carlezon et al, 1998), whereas CREB overexpression in the NAc attenuates cocaineinduced locomotor sensitization (Sakai et al, 2002) and CPP (Carlezon et al, 1998; Pliakas et al, 2001). These findings suggest that CREB activation mediates tolerance to the reinforcing effects of cocaine. Given that pCREB provides negative modulation of behavioral responses to cocaine, we suspect that the increase in CREB activation may provide another mechanism by which rolipram attenuates cocaineinduced CPP. However, it should be noted that CREB has a complex influence on behavioral responses to cocaine. CREBdeficient mice exhibit enhanced CPP and locomotor sensitization in response to repeated cocaine exposure (Walters and Blendy, 2001). Overexpression of CREB in the NAc increases cocaine self-administration (Larson et al, 2011). Nevertheless, CREB is an important downstream target of rolipram and may be critically involved in rolipram-induced attenuation of cocaine CPP.

Systemic administration of rolipram blocked cocaineinduced locomotor sensitization (Janes et al, 2009), selfadministration (Knapp et al, 1999) and CPP (Thompson et al, 2004) but did not affect CPP to food (Thompson et al, 2004). Rolipram also blocked methamphetamine-induced 

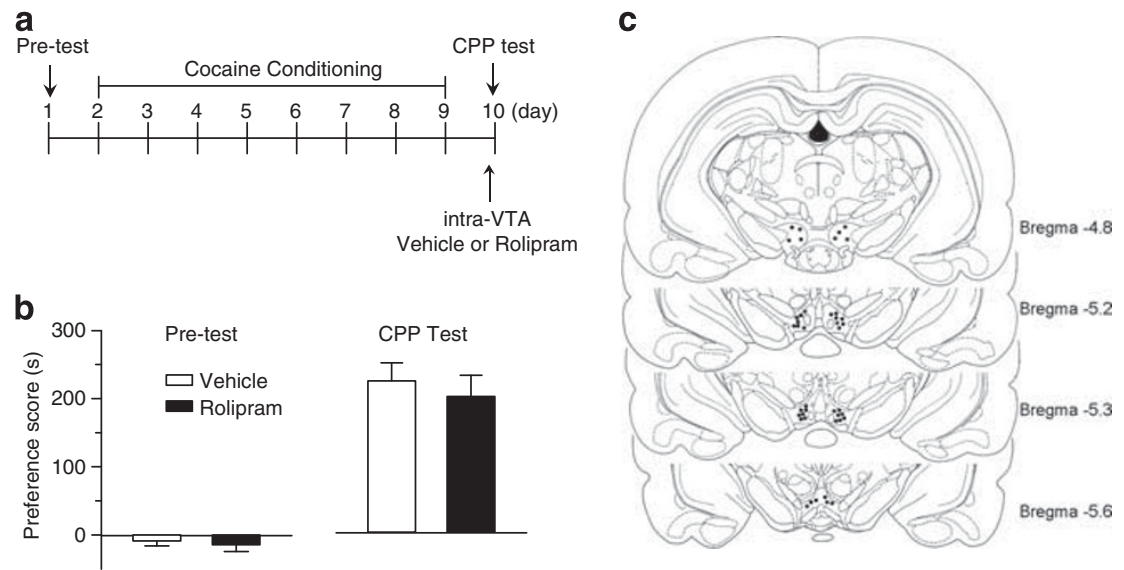

Figure 5 Intra-VTA infusion of rolipram 20 min before CPP test did not affect the expression of CPP to cocaine. (a) Timeline of drug treatment and behavioral paradigm. Rats received only cocaine place conditioning. Vehicle $(|\mu|)$ or rolipram $(0.5 \mu \mathrm{g},|\mu|)$ was bilaterally infused into the VTA 20 min before the CPP test. (b) Cocaine conditioning induced significant increase in CPP scores compared with pre-test. Intra-VTA infusion of rolipram before the CPP test did not significantly affect CPP scores $(n=6-9, p>0.05)$. Error bars indicate SEM. (c) Representative cannula placements in the VTA. Location of injection sites in the VTA from the behavioral data summarized in Figures 5 and $6 \mathrm{~b}$.

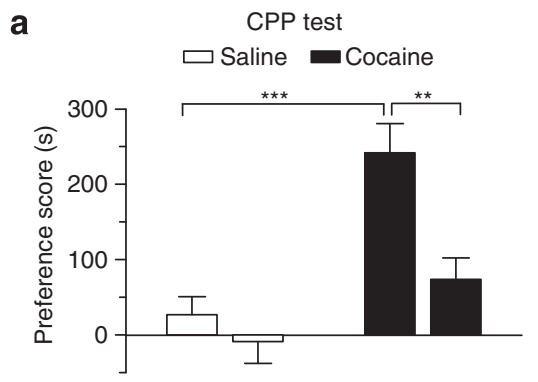

i.p. injection Vehicle Rolipram Vehicle Rolipram

C
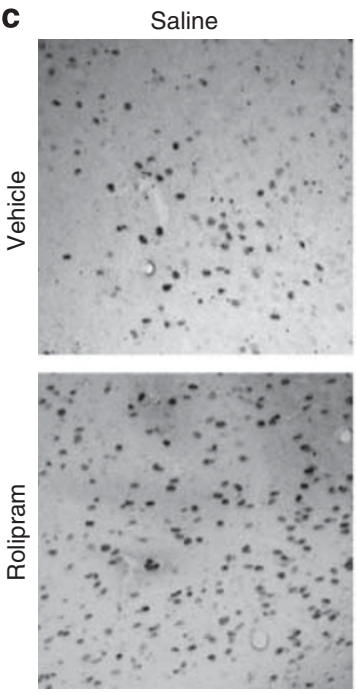

b
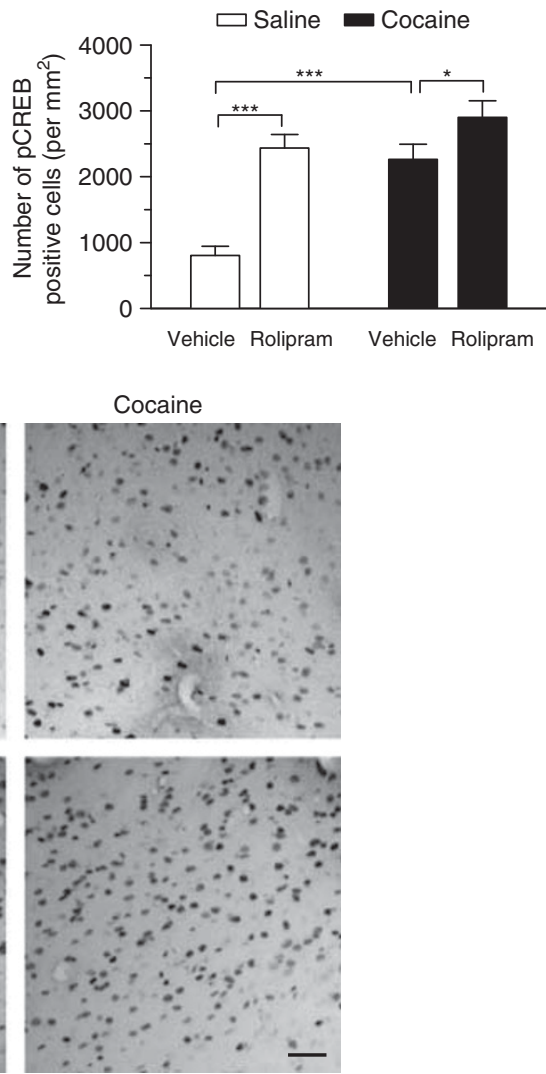

Figure 6 I.p. injections of the PDE4 inhibitor rolipram attenuated cocaine CPP and increased PCREB in the VTA. Groups of rats received saline and cocaine $(15 \mathrm{mg} / \mathrm{kg}$ ) place conditioning once daily for 8 days. Vehicle or rolipram (I mg/kg) was i.p. injected 20 min before each saline- or cocaine-pairing. (a) I.p. injection of rolipram significantly attenuated CPP in cocaine-conditioned rats but did not affect CPP scores in saline-conditioned rats $(n=6$ each group; $* * p<0.0 \mathrm{I}$, *** $p<0.00 \mathrm{I}$ ). (b) Summary bar graphs show that either cocaine conditioning or rolipram treatment significantly increased the number of pCREB-positive cells in the VTA (**** $<0.00 \mathrm{I}$ ). Rolipram significantly enhanced cocaine-induced increase in the number of pCREB-positive cells $(n=6$ rats; ${ }^{*} p<0.05$ ). Error bars indicate SEM. (c) Representative sections show pCREB-positive immunostaining in the VTA. Scale bar: $40 \mu \mathrm{m}$.

locomotor sensitization and stereotyped behavior (Iyo et al, 1995, 1996), and morphine-induced CPP (Thompson et al, 2004). We also demonstrated that i.p. injections rolipram blocked the acquisition of cocaine CPP. These results indicate that PDE4 inhibition reduces behavioral effects of a variety of addictive drugs but does not affect natural 
$\mathrm{TH}$

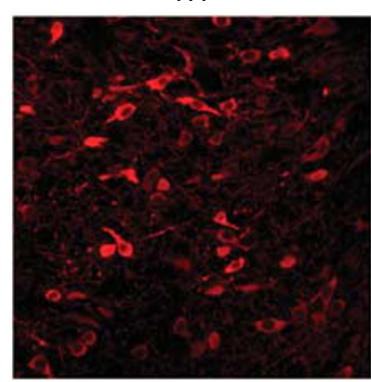

pCREB

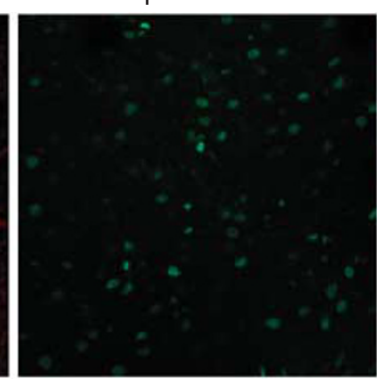

Merge

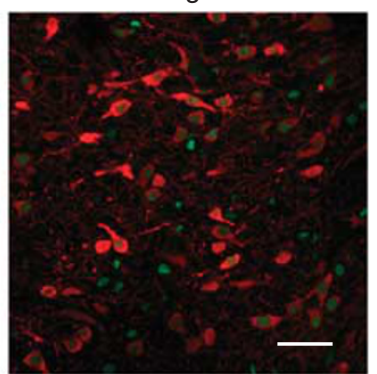

Figure 7 Dual immunofluorescence staining for pCREB (green) and tyrosine hydroxylase (TH, red) in VTA sections from rolipram plus cocaine-treated rats $(n=3$ rats). Scale bar: $50 \mu \mathrm{m}$

rewards. Rolipram enhances the acquisition, consolidation, and retrieval of certain forms of memories (Barad et al, 1998; Li et al, 2011; Vecsey et al, 2009; Zhang et al, 2000, 2004). It seems unlikely that rolipram reduces drug-seeking behavior by impairing drug-cue associative learning. Pharmacological and genetic manipulations of cAMP/PKA signaling pathway significantly altered cocaine-seeking behavior. Enhancing cAMP signaling with cAMP analogs or stimulators altered cocaine-induced locomotor sensitization and self-administration (Lynch and Taylor, 2005; Self et al, 1998; Tolliver et al, 1996). Mice lacking cAMPgenerating enzymes adenylyl cyclase types 1 and 8 fail to display locomotor sensitization after chronic cocaine treatment (DiRocco et al, 2009). PDE4 inhibition-induced activation of cAMP/PKA interferes with dopamine receptor signaling, which could lead to the inhibition of the subjective rewarding sensations of the addictive drugs (Thompson et al, 2004). At molecular and cellular levels, the PDE4 inhibitors block I-LTD and increase pCREB expression. Together, these mechanisms might explain why PDE4 inhibitors attenuate cocaine-seeking behavior.

This study has identified VTA as a target brain region that mediates, at least in part, the behavioral effects of systemic administration of PDE4 inhibitors. However, other brain regions such as the NAc may also be an important target of PDE4 inhibitors. Indeed, PDE4B, an isoform of PDE4, is highly expressed in the NAc (Cherry and Davis, 1999), whereas rolipram inhibits all four PDE4 isoforms (Ke, 2004). Brain regions such as the NAc may be recruited subsequently to maintain CPP to cocaine (Miller and Marshall, 2005; Valjent et al, 2005), which may explain why intra-VTA microinjection of rolipram did not affect the expression of cocaine CPP when applied just before the CPP test.

Although the behavioral studies and immunohistochemistry were carried out in adult rats, whole-cell recordings were made in slices prepared from juvenile rats because of the technical difficulty in making long-term recordings from a long number of neurons in adult midbrain slices. The functional significance of our data should be interpreted with caution because of the age difference of the animals.

In summary, we have identified potential mechanisms and brain region that may be involved in the effects of PDE4 inhibitors on cocaine CPP. PDE4 inhibitors have reached the clinical trial stage for the treatment of chronic obstructive pulmonary disease and other diseases (Diamant and Spina, 2011). Given the consistent effects in reducing drug-seeking behaviors (Iyo et al, 1995, 1996; Janes et al, 2009; Knapp et al, 1999; Thompson et al, 2004), PDE4 inhibitors are a promising candidate for therapeutic intervention of drug addiction. Understanding the underlying mechanisms for their action will be an important step toward this goal.

\section{ACKNOWLEDGEMENTS}

This work was supported by National Institutes of Health Grants DA024741.

\section{DISCLOSURE}

The authors declare no conflict of interest.

\section{Author contributions}

PZ, WW, and QSL designed the experiments. PZ, WW, FY, $\mathrm{MN}$, and XJL performed the experiments, collected, and analyzed the data. PZ and QSL drafted the manuscript.

\section{REFERENCES}

Anderson SM, Pierce RC (2005). Cocaine-induced alterations in dopamine receptor signaling: implications for reinforcement and reinstatement. Pharmacol Ther 106: 389-403.

Awad JA, Johnson RA, Jakobs KH, Schultz G (1983). Interactions of forskolin and adenylate cyclase. Effects on substrate kinetics and protection against inactivation by heat and N-ethylmaleimide. J Biol Chem 258: 2960-2965.

Barad M, Bourtchouladze R, Winder DG, Golan H, Kandel E (1998). Rolipram, a type IV-specific phosphodiesterase inhibitor, facilitates the establishment of long-lasting long-term potentiation and improves memory. Proc Natl Acad Sci USA 95: 15020-15025.

Carlezon Jr WA, Thome J, Olson VG, Lane-Ladd SB, Brodkin ES, Hiroi N et al (1998). Regulation of cocaine reward by CREB. Science (New York, NY) 282: 2272-2275.

Chaperon F, Soubrie P, Puech AJ, Thiebot MH (1998). Involvement of central cannabinoid (CB1) receptors in the establishment of place conditioning in rats. Psychopharmacology 135: 324-332.

Chen CC, Yang CH, Huang CC, Hsu KS (2010). Acute stress impairs hippocampal mossy fiber-CA3 long-term potentiation by enhancing cAMP-specific phosphodiesterase 4 activity. Neuropsychopharmacology 35: 1605-1617.

Cherry JA, Davis RL (1999). Cyclic AMP phosphodiesterases are localized in regions of the mouse brain associated with reinforcement, movement, and affect. J Comp Neurol 407: 287-301. 
Chiu CQ, Puente N, Grandes P, Castillo PE (2010). Dopaminergic modulation of endocannabinoid-mediated plasticity at GABAergic synapses in the prefrontal cortex. J Neurosci 30: 7236-7248.

Conti M, Richter W, Mehats C, Livera G, Park JY, Jin C (2003). Cyclic AMP-specific PDE4 phosphodiesterases as critical components of cyclic AMP signaling. J Biol Chem 278: 5493-5496.

Diamant Z, Spina D (2011). PDE4-inhibitors: a novel, targeted therapy for obstructive airways disease. Pulm Pharmacol Ther 24: $353-360$.

DiRocco DP, Scheiner ZS, Sindreu CB, Chan GC, Storm DR (2009). A role for calmodulin-stimulated adenylyl cyclases in cocaine sensitization. J Neurosci 29: 2393-2403.

Elliott JM, Beveridge TJ (2005). Psychostimulants and monoamine transporters: upsetting the balance. Curr Opin Pharmacol 5: 94-100.

Iyo M, Bi Y, Hashimoto K, Inada T, Fukui S (1996). Prevention of methamphetamine-induced behavioral sensitization in rats by a cyclic AMP phosphodiesterase inhibitor, rolipram. Eur J Pharmacol 312: 163-170.

Iyo M, Maeda Y, Inada T, Kitao Y, Sasaki H, Fukui S (1995). The effects of a selective cAMP phosphodiesterase inhibitor, rolipram, on methamphetamine-induced behavior. Neuropsychopharmacology 13: 33-39.

Janes AC, Kantak KM, Cherry JA (2009). The involvement of type IV phosphodiesterases in cocaine-induced sensitization and subsequent pERK expression in the mouse nucleus accumbens. Psychopharmacology 206: 177-185.

Johnson SW, North RA (1992). Two types of neurone in the rat ventral tegmental area and their synaptic inputs. J Physiol 450: $455-468$.

Jones S, Kauer JA (1999). Amphetamine depresses excitatory synaptic transmission via serotonin receptors in the ventral tegmental area. J Neurosci 19: 9780-9787.

$\mathrm{Ke} \mathrm{H}$ (2004). Implications of PDE4 structure on inhibitor selectivity across PDE families. Int J Impot Res 16(Suppl 1): S24-S27.

Knapp CM, Foye MM, Ciraulo DA, Kornetsky C (1999). The type IV phosphodiesterase inhibitors, Ro 20-1724 and rolipram, block the initiation of cocaine self-administration. Pharmacol Biochem Behav 62: 151-158.

Larson EB, Graham DL, Arzaga RR, Buzin N, Webb J, Green TA et al (2011). Overexpression of CREB in the nucleus accumbens shell increases cocaine reinforcement in self-administering rats. J Neurosci 31: 16447-16457.

Li YF, Cheng YF, Huang Y, Conti M, Wilson SP, O'Donnell JM et al (2011). Phosphodiesterase-4D knock-out and RNA interferencemediated knock-down enhance memory and increase hippocampal neurogenesis via increased cAMP signaling. J Neurosci 31: 172-183.

Li YF, Huang Y, Amsdell SL, Xiao L, O'Donnell JM, Zhang HT (2009). Antidepressant- and anxiolytic-like effects of the phosphodiesterase- 4 inhibitor rolipram on behavior depend on cyclic AMP response element binding protein-mediated neurogenesis in the hippocampus. Neuropsychopharmacology 34: 2404-2419.

Liu QS, Pu L, Poo MM (2005). Repeated cocaine exposure in vivo facilitates LTP induction in midbrain dopamine neurons. Nature 437: 1027-1031.

Lu L, Grimm JW, Shaham Y, Hope BT (2003). Molecular neuroadaptations in the accumbens and ventral tegmental area during the first 90 days of forced abstinence from cocaine selfadministration in rats. J Neurochem 85: 1604-1613.

Lugnier C (2006). Cyclic nucleotide phosphodiesterase (PDE) superfamily: a new target for the development of specific therapeutic agents. Pharmacol Ther 109: 366-398.

Lynch WJ, Taylor JR (2005). Persistent changes in motivation to self-administer cocaine following modulation of cyclic AMPdependent protein kinase A (PKA) activity in the nucleus accumbens. Eur J Neurosci 22: 1214-1220.
Maisonneuve IM, Kreek MJ (1994). Acute tolerance to the dopamine response induced by a binge pattern of cocaine administration in male rats: an in vivo microdialysis study. J Pharmacol Exp Ther 268: 916-921.

Maldonado R, Saiardi A, Valverde O, Samad TA, Roques BP, Borrelli E (1997). Absence of opiate rewarding effects in mice lacking dopamine D2 receptors. Nature 388: 586-589.

Marin MT, Berkow A, Golden SA, Koya E, Planeta CS, Hope BT (2009). Context-specific modulation of cocaine-induced locomotor sensitization and ERK and CREB phosphorylation in the rat nucleus accumbens. Eur J Neurosci 30: 1931-1940.

Miller CA, Marshall JF (2005). Molecular substrates for retrieval and reconsolidation of cocaine-associated contextual memory. Neuron 47: 873-884.

Miro X, Perez-Torres S, Puigdomenech P, Palacios JM, Mengod G (2002). Differential distribution of PDE4D splice variant mRNAs in rat brain suggests association with specific pathways and presynaptical localization. Synapse 45: 259-269.

Mori T, Baba J, Ichimaru Y, Suzuki T (2000). Effects of rolipram, a selective inhibitor of phosphodiesterase 4, on hyperlocomotion induced by several abused drugs in mice. Jpn J Pharmacol 83: $113-118$.

Navakkode S, Sajikumar S, Frey JU (2004). The type IV-specific phosphodiesterase inhibitor rolipram and its effect on hippocampal long-term potentiation and synaptic tagging. J Neurosci 24: 7740-7744.

Nestler EJ (2001). Molecular basis of long-term plasticity underlying addiction. Nat Rev Neurosci 2: 119-128.

Neve KA, Seamans JK, Trantham-Davidson H (2004). Dopamine receptor signaling. J Recept Signal Transduct Res 24: 165-205.

Olson VG, Zabetian CP, Bolanos CA, Edwards S, Barrot M, Eisch $\mathrm{AJ}$ et al (2005). Regulation of drug reward by cAMP response element-binding protein: evidence for two functionally distinct subregions of the ventral tegmental area. J Neurosci 25: 5553-5562.

Pan B, Hillard CJ, Liu QS (2008a). Endocannabinoid signaling mediates cocaine-induced inhibitory synaptic plasticity in midbrain dopamine neurons. J Neurosci 28: 1385-1397.

Pan B, Hillard CJ, Liu QS (2008b). D2 dopamine receptor activation facilitates endocannabinoid-mediated long-term synaptic depression of GABAergic synaptic transmission in midbrain dopamine neurons via cAMP-protein kinase A signaling. J Neurosci 28: 14018-14030.

Pan B, Zhong P, Sun D, Liu QS (2011). Extracellular signalregulated kinase signaling in the ventral tegmental area mediates cocaine-induced synaptic plasticity and rewarding effects. J Neurosci 31: 11244-11255.

Paxinos G, Watson C (1986). The Rat Brain in Stereotaxic Coordinates, Compact 3rd edn. Academic Press: Sydney, Orlando.

Pliakas AM, Carlson RR, Neve RL, Konradi C, Nestler EJ, Carlezon Jr WA (2001). Altered responsiveness to cocaine and increased immobility in the forced swim test associated with elevated cAMP response element-binding protein expression in nucleus accumbens. J Neurosci 21: 7397-7403.

Rutten K, Misner DL, Works M, Blokland A, Novak TJ, Santarelli L et al (2008). Enhanced long-term potentiation and impaired learning in phosphodiesterase 4D-knockout (PDE4D) mice. Eur J Neurosci 28: 625-632.

Sakai N, Thome J, Newton SS, Chen J, Kelz MB, Steffen C et al (2002). Inducible and brain region-specific CREB transgenic mice. Mol Pharmacol 61: 1453-1464.

Self DW, Genova LM, Hope BT, Barnhart WJ, Spencer JJ, Nestler EJ (1998). Involvement of cAMP-dependent protein kinase in the nucleus accumbens in cocaine self-administration and relapse of cocaine-seeking behavior. J Neurosci 18: 1848-1859.

Silva AJ, Kogan JH, Frankland PW, Kida S (1998). CREB and memory. Annu Rev Neurosci 21: 127-148. 
Swanson LW (1982). The projections of the ventral tegmental area and adjacent regions: a combined fluorescent retrograde tracer and immunofluorescence study in the rat. Brain Res Bull 9: 321-353.

Thompson BE, Sachs BD, Kantak KM, Cherry JA (2004). The type IV phosphodiesterase inhibitor rolipram interferes with druginduced conditioned place preference but not immediate early gene induction in mice. Eur J Neurosci 19: 2561-2568.

Tolliver BK, Ho LB, Reid MS, Berger SP (1996). Evidence for involvement of ventral tegmental area cyclic AMP systems in behavioral sensitization to psychostimulants. J Pharmacol Exp Ther 278: 411-420.

Valjent E, Pascoli V, Svenningsson P, Paul S, Enslen H, Corvol JC et al (2005). Regulation of a protein phosphatase cascade allows convergent dopamine and glutamate signals to activate ERK in the striatum. Proc Natl Acad Sci USA 102: 491-496.

Vecsey CG, Baillie GS, Jaganath D, Havekes R, Daniels A, Wimmer $\mathrm{M}$ et al (2009). Sleep deprivation impairs cAMP signalling in the hippocampus. Nature 461: 1122-1125.
Walters CL, Blendy JA (2001). Different requirements for cAMP response element binding protein in positive and negative reinforcing properties of drugs of abuse. J Neurosci 21: 9438-9444.

Walters CL, Kuo YC, Blendy JA (2003). Differential distribution of CREB in the mesolimbic dopamine reward pathway. $J$ Neurochem 87: 1237-1244.

Zhang HT (2009). Cyclic AMP-specific phosphodiesterase-4 as a target for the development of antidepressant drugs. Curr Pharmaceutical Design 15: 1688-1698.

Zhang HT, Crissman AM, Dorairaj NR, Chandler LJ, O'Donnell JM (2000). Inhibition of cyclic AMP phosphodiesterase (PDE4) reverses memory deficits associated with NMDA receptor antagonism. Neuropsychopharmacology 23: 198-204.

Zhang HT, Zhao Y, Huang Y, Dorairaj NR, Chandler LJ, O'Donnell JM (2004). Inhibition of the phosphodiesterase 4 (PDE4) enzyme reverses memory deficits produced by infusion of the MEK inhibitor U0126 into the CA1 subregion of the rat hippocampus. Neuropsychopharmacology 29: 1432-1439. 